\title{
Combined use of cardiopulmonary ultrasound in the diagnosis of pulmonary edema in patients with heart failure: a retrospective analysis
}

\author{
Mengjun Shen, Hongwei Chen, Yang Cong \\ Department of Ultrasound, Shanghai Pulmonary Hospital, Tongji University, Shanghai, China \\ Contributions: (I) Conception and design: M Shen, Y Cong; (II) Administrative support: M Shen, Y Cong; (III) Provision of study materials or \\ patients: M Shen, Y Cong; (IV) Collection and assembly of data: Y Cong; (V) Data analysis and interpretation: M Shen; (VI) Manuscript writing: All \\ authors; (VII) Final approval of manuscript: All authors. \\ Correspondence to: Yang Cong. Department of Ultrasound, Shanghai Pulmonary Hospital, Tongji University, 507 Zheng Min Road, Shanghai, China. \\ Email: yangcong_cc08@163.com.
}

\begin{abstract}
Background: Heart failure (HF) is generally complicated with pulmonary edema (PE), the early diagnosis and treatment is essential. We aimed to evaluate the effects of combined use of cardiopulmonary ultrasound in the diagnosis of PE in HF patients, to provide reference for the management of HF.

Methods: HF patients treated in our hospital from January 1, 2019 to June 30, 2020 were included. All patients underwent echocardiography and lung ultrasonography, and analyzed the characteristics of patients and related detected results. Logistic regression analyses were conducted to identify the potential risk factors. And the receiver operating characteristic (ROC) curve was conducted to compare the predictive value of factors.

Results: A total of $183 \mathrm{HF}$ patients were included, the incidence of PE in HF patients was $62.84 \%$. Logistic regression analyses indicated that NT-proBNP (OR 2.24, 95\% CI: 1.28-5.04), LAVI (OR 2.03, 95\% CI: 1.02-4.45), E/e' (OR 1.57, 95\% CI: 0.13-2.28), SPAP (OR 1.35, 95\% CI: 0.02-2.84) were the independent risk factors for $\mathrm{PE}$ in patients with $\mathrm{HF}$ (all $\mathrm{P}<0.05$ ). The AUC of NT-proBNP, LAVI, E/e' and SPAP were $0.705,0.668,0.674$ and 0.691 respectively. NT-proBNP $\geq 8,842.37 \mathrm{ng} / \mathrm{L}, \mathrm{LAVI} \geq 42.14 \mathrm{~mL} / \mathrm{m}^{2}$, $\mathrm{E} / \mathrm{e}^{\prime} \geq 19.20$, SPAP $\geq 38.16 \mathrm{mmHg}$ were the independent risk factors for $\mathrm{PE}$ in patients with $\mathrm{HF}$ (all $\mathrm{P}<0.05$ ).

Conclusions: Combined use of cardiopulmonary ultrasound is beneficial to the early diagnosis of PE in patients with HF, and early interventions are needed for those patients with risk factors.
\end{abstract}

Keywords: Cardiopulmonary; ultrasound; pulmonary edema (PE); heart failure (HF); risk; treatment

Submitted Aug 21, 2020. Accepted for publication Sep 20, 2020.

doi: $10.21037 / \mathrm{cdt}-20-733$

View this article at: http://dx.doi.org/10.21037/cdt-20-733

\section{Introduction}

Heart failure (HF) patients have high mortality and poor prognosis, and it has now become the leading cause of death in patients with cardiovascular disease (1). According to the survey (2), the current number of HF patients worldwide has reached about 24.5 million, and it is still increasing at a rate of over 2 million per year. It's been reported that the prevalence of $\mathrm{HF}$ in adult patients is about $0.9 \%$, and the mortality of HF among hospitalized patients is about
8.9\% (3). Clinically, the onset of HF is rapid and serious, and the symptoms and signs are often atypical. Therefore, the early diagnosis of $\mathrm{HF}$ is still difficult $(4,5)$. It's necessary to identify the effective and convenient methods to promote the early diagnosis of HF.

Pulmonary edema (PE) refers to the imbalance of the production and return of tissue fluid in the lung due to some reasons, so that a large amount of tissue fluid cannot be absorbed by the pulmonary lymph and pulmonary 
venous system in a short period of time. It leaks from the pulmonary capillaries and accumulates in the alveoli and lung interstitium, causing serious obstacles to lung ventilation and ventilation. Clinically, it is characterized by extreme dyspnea, sitting breathing, cyanosis, profuse sweating, paroxysmal cough accompanied by a large amount of white or pink foamy sputum, and the lungs are full of symmetrical wet rales. As an important sign of $\mathrm{HF}, \mathrm{PE}$ has long been mainly dependent on chest X-ray or CT examination (6). Although bedside chest X-ray is more convenient, it also has its limitations. In addition to radiation, it is also affected by organs and tissues in the shadow of the mediastinum, such as the esophagus, trachea, and lymph nodes etc. (7). However, chest CT radiation is larger, which limits repeated use. Therefore, we still need to find new inspection methods to improve the sensitivity and specificity of the diagnosis of HF, and to determine the severity of the disease (8). With the continuous deepening of clinical research, the value of bedside cardiopulmonary ultrasound in detecting different lung diseases and pleural lesions has been reassessed. It has advantages of feasible bedside, non-radioactive, reusable and low cost. Therefore, we aimed to use cardiopulmonary ultrasound to compare the differences in clinical and echocardiographic parameters between HF patients with and without $\mathrm{PE}$, and to evaluate the relationship between the patient's clinical manifestations and echocardiographic parameters, thereby providing evidence for the management of HF patients. We present the following article in accordance with the STARD reporting checklist (available at http://dx.doi.org/10.21037/ cdt-20-733).

\section{Methods}

\section{Ethical considerations}

Our study is a retrospective study. The study was conducted in accordance with the Declaration of Helsinki (as revised in 2013). The study was approved by the ethics committee of our hospital (No. 2018026) and informed consent was taken from all the patients.

\section{Patients}

HF patients treated in our hospital from January 1, 2019 to June 30, 2020 were included. The inclusion criteria were as follows: (I) adult patients with age $\geq 18$ years; (II) the diagnosis of HF was complied with related guidelines $(9,10)$;
(III) patients were informed and agreed to participants in this study. Patients were excluded if they were: (I) aged $<18$ years; (II) patients with atrial fibrillation, mitral stenosis and lung cancers; (III) patients who disagreed to participants in this study.

\section{Ultrasound detection}

The instrument used in this present study was Philips DX 150 ultrasonic diagnostic apparatus, the frequency of L5-1 phased array probe was $1-5 \mathrm{MHz}$, and the frequency of L12-3 linear array probe is $3-12 \mathrm{MHz}$.

Echocardiography was performed as follows: all patients were in a supine, semi-recumbent or lateral position. Echocardiographic measurement standards are based on the Heart Cavity Quantitative Guidelines $M$ of the American Society of Echocardiography and the European Association of Cardiovascular Imaging (ASE/EACVE). The long axis view of the left ventricle was measured under M-mode echocardiography to measure left ventricular end-diastolic diameters (LVEDD) and left ventricular end-systolic diameters (LVESD). The apical two-chamber and fourchamber biplane Simpson method was used to measure left ventricular end-diastolic volumes (LVEDV), left ventricular end-systolic volumes (LVESV), and left ventricular evacuation. Left ventricular ejection fraction (LVEF) and left atrial volume (LAV), and normalized with body surface area to obtain left atrial volume index (LAVI). The apical four-chamber view with the right ventricle as the center was used to measure the diameter of right ventricle (RVD). The apical four-chamber view of the mitral valve measured the early diastolic flow velocity $\mathrm{E}$ peak and late diastolic flow velocity A peak. We placed a sample volume of $1.5 \mathrm{~mm}$ on the septal and lateral sides of the mitral annulus, and measured the early diastolic e', and calculated the average $\mathrm{n} / \mathrm{e}$ '. The degree of mitral regurgitation was semi-quantitative with color Doppler, and the regurgitation was divided into mild, moderate and severe. The systolic pulmonary artery pressure (SPAP) was estimated by the tricuspid regurgitation pressure difference plus the right atrial pressure. The right atrial pressure was estimated based on the inner diameter of the inferior vena cava and the rate of inspiratory collapse. In addition, we classified the left ventricular diastolic function according to the 2016 updated ASE/EACVE left ventricular diastolic function guidelines $(9,11)$.

The steps of lung ultrasound detection were as follows: the patient took the supine or semi-recumbent position, and the left and right scan ranges included the anterior and 
lateral chest walls, that is, from the parasternal line to the posterior axillary line. And the probe was scanned along the intercostal space and perpendicular to the chest wall during scanning. In this study, the diagnosis of cardiogenic PE by pulmonary ultrasound was based on the results of previous studies, which showed bilateral multiple B-lines (spacing $\leq 7 \mathrm{~mm}$ ) combined with smooth pleural lines.

\section{Data collection}

All patients underwent echocardiography and lung ultrasonography. The related ultrasonography parameters mentioned above were taken as the primary outcomes. Furthermore, we collected and recorded the patient's characteristics, including weight, age and other related information. And we collected the level of N-terminal probrain natriuretic peptide (NT-proBNP) and NYHA cardiac function classification.

\section{Statistical analysis}

We used SPSS 22.0 software for statistical analysis. Continuous data were expressed as mean \pm standard deviation, and count data were expressed as percentage. Comparisons between groups were conducted with student $t$-test or chi-square test. Logistic regression analyses were conducted to identify the potential risk factors. According to the receiver operating characteristic (ROC) curve, the thresholds for predicting the occurrence of SHS were determined. And the area under the ROC curve (AUC) was used to compare the predictive value of factors, and to evaluate its sensitivity and specificity, positive and negative predictive values. We used the point with the largest Youden index for cutoff value calculation. In this present study, $\mathrm{P}<0.05$ was considered statistically significant.

\section{Results}

\section{The characteristics of included patients}

A total of $183 \mathrm{HF}$ patients were included, of which 115 patients were diagnosed as $\mathrm{PE}$, the incidence of $\mathrm{PE}$ in $\mathrm{HF}$ patients was $62.84 \%$. As presented in Table 1 , there were no significant difference in the gender and age between two groups (all $\mathrm{P}>0.05$ ), and there were significant differences in the classification of left ventricular diastolic function, NYHA classification, NT-proBNP, LVEDD, LVEDV, LVEF, LAVI, E/e', RVD and SPAP (all $\mathrm{P}<0.05$ ).

\section{The risk factors of PE in patients with $H F$}

The significant variables in univariate analyses were further included for logistic regression analyses. As presented in Table 2, the logistic regression analyses indicated that NTproBNP (OR 2.24, 95\% CI: 1.28-5.04), LAVI (OR 2.03, 95\% CI: 1.02-4.45), E/e' (OR 1.57, 95\% CI: 0.13-2.28), SPAP (OR 1.35, 95\% CI: 0.02-2.84) were the independent risk factors for $\mathrm{PE}$ in patients with $\mathrm{HF}$ (all $\mathrm{P}<0.05$ ).

\section{The predictive value of NT-proBNP, LAVI, E/e' and SPAP for the PE}

Figure 1 presented the ROC of NT-proBNP, LAVI, E/e' and SPAP for the PE. As indicated in Table 3, the AUC of NT-proBNP, LAVI, E/e' and SPAP were $0.705,0.668,0.674$ and 0.691 respectively. NT-proBNP $\geq 8,842.37 \mathrm{ng} / \mathrm{L}$, LAVI $\geq 42.14 \mathrm{~mL} / \mathrm{m}^{2}, \mathrm{E} / \mathrm{e}^{\prime} \geq 19.20, \mathrm{SPAP} \geq 38.16 \mathrm{mmHg}$ were the independent risk factors for $\mathrm{PE}$ in patients with $\mathrm{HF}$ (all $\mathrm{P}<0.05)$.

\section{Discussion}

$\mathrm{HF}$ is a common clinical disease, which is generally complicated combined with pulmonary congestion (12). $\mathrm{HF}$ is the main syndrome of organic cardiovascular disease caused by different causes, and it is a common clinical critical illness (13). According to reports, the incidence of HF patients shows a significant increase with age $(14,15)$. Despite the continuous improvement of its treatment methods, the annual mortality of patients with $\mathrm{HF}$ is still as high as $8.9 \%$, and the 5 -year mortality is as high as $50 \%$, even exceeding the mortality of many malignant tumors (16). Therefore, how to diagnose HF more conveniently and timely is of great significance to the early prevention and treatment of HF. The results of this study have indicated that NT-proBNP $\geq 8,842.37 \mathrm{ng} / \mathrm{L}$, LAVI $\geq 42.14 \mathrm{~mL} / \mathrm{m}^{2}, \mathrm{E} / \mathrm{e}^{\prime} \geq 19.20, \mathrm{SPAP} \geq 38.16 \mathrm{mmHg}$ were the independent risk factors for $\mathrm{PE}$ in patients with $\mathrm{HF}$, which can provide significant implications for clinical treatment of HF.

Previous studies (17-19) have found that HF patients with $\mathrm{PE}$ have lower LVEF, more severe diastolic dysfunction, larger left and right ventricles, and higher SPAP, which is consistent with our findings. When the patient has left ventricular systolic and/or diastolic dysfunction, the left ventricular end diastolic pressure and left atrial pressure increase accordingly, which cause the 
Table 1 The characteristics of included patients

\begin{tabular}{|c|c|c|c|c|}
\hline Variables & No-PE group $(n=68)$ & PE group $(n=115)$ & $t / \chi^{2}$ & $P$ \\
\hline Age (years) & $64.42 \pm 9.33$ & $65.01 \pm 10.28$ & 15.301 & 0.061 \\
\hline Classification of left ventricular diastolic function & & & 1.212 & 0.015 \\
\hline I level & $43(63.24 \%)$ & $18(15.65 \%)$ & & \\
\hline III level & $6(8.82 \%)$ & $40(34.78 \%)$ & & \\
\hline NYHA classification & & & 1.168 & 0.008 \\
\hline I level & $20(29.41 \%)$ & $0(0 \%)$ & & \\
\hline Il level & $45(66.18 \%)$ & $37(32.17 \%)$ & & \\
\hline NT-proBNP (ng/L) & $1,190.47 \pm 395.08$ & $9,822.16 \pm 895.41$ & 84.104 & 0.001 \\
\hline LVEDD (mm) & $58.24 \pm 12.10$ & $62.17 \pm 13.45$ & 17.299 & 0.036 \\
\hline LVEDV (mL) & $152.37 \pm 44.03$ & $169.54 \pm 53.14$ & 37.469 & 0.063 \\
\hline LVEF (\%) & $38.40 \pm 11.28$ & $34.01 \pm 10.12$ & 10.664 & 0.033 \\
\hline LAVI $\left(\mathrm{mL} / \mathrm{m}^{2}\right)$ & $39.16 \pm 10.24$ & $47.35 \pm 11.42$ & 9.179 & 0.012 \\
\hline$E / e^{\prime}$ & $15.29 \pm 3.05$ & $22.16 \pm 4.65$ & 3.268 & 0.017 \\
\hline RVD (mm) & $31.36 \pm 4.41$ & $37.74 \pm 4.97$ & 5.177 & 0.042 \\
\hline SPAP (mmHg) & $30.18 \pm 3.24$ & $45.91 \pm 4.14$ & 3.075 & 0.015 \\
\hline
\end{tabular}

LVEDD, left ventricular end-diastolic diameters; LVEDV, left ventricular end-diastolic volumes; LVEF, left ventricular ejection fraction; LAVI, left atrial volume index; RVD, diameter of right ventricle; SPAP, systolic pulmonary artery pressure.

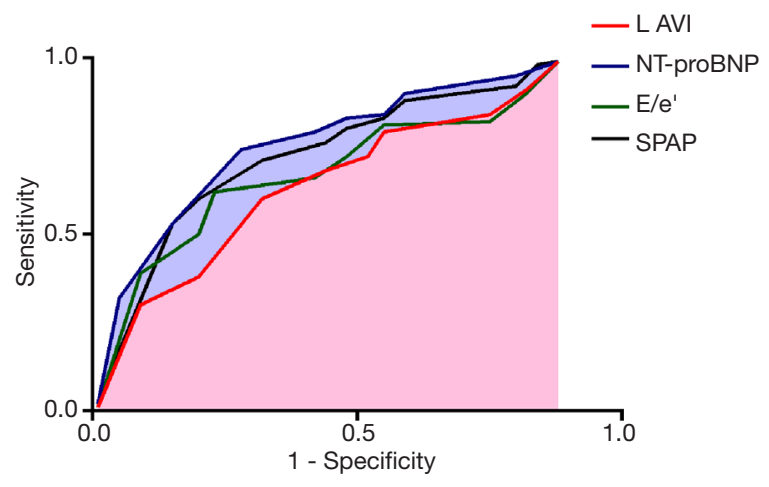

Figure 1 The ROC of NT-proBNP, LAVI, E/e' and SPAP for the PE. ROC, receiver operating characteristic; LAVI, left atrial volume index; SPAP, systolic pulmonary artery pressure; PE, pulmonary edema.
Table 2 Logistic regression analysis on the risk factors of PE

\begin{tabular}{lccccc}
\hline Variables & $\beta$ & SE & OR & $95 \% \mathrm{Cl}$ & $\mathrm{P}$ \\
\hline NT-proBNP & 0.85 & 0.13 & 2.24 & $1.28-5.04$ & 0.013 \\
LAVI & 0.94 & 0.25 & 2.03 & $1.02-4.45$ & 0.021 \\
E/e' & 0.74 & 0.41 & 1.57 & $0.13-2.28$ & 0.042 \\
SPAP & 0.92 & 0.32 & 1.35 & $0.02-2.84$ & 0.030 \\
\hline
\end{tabular}

PE, pulmonary edema; LAVI, left atrial volume index; SPAP, systolic pulmonary artery pressure. 
Table 3 The predictive value of NT-proBNP, LAVI, E/e' and SPAP for the PE

\begin{tabular}{lccccc}
\hline Variables & Cutoff value & AUC & $95 \% \mathrm{Cl}$ & Sensitivity (\%) & Specificity (\%) \\
\hline NT-proBNP $(\mathrm{ng} / \mathrm{L})$ & $8,842.37$ & 0.705 & $0.628-0.784$ & 80.24 & 83.18 \\
LAVI $\left(\mathrm{mL} / \mathrm{m}^{2}\right)$ & 42.14 & 0.668 & $0.602-0.787$ & 73.52 & 72.45 \\
E/e' & 19.20 & 0.674 & $0.524-0.753$ & 81.22 \\
SPAP $(\mathrm{mmHg})$ & 38.16 & 0.691 & $0.604-0.779$ & 79.18 & 80.13 \\
\hline
\end{tabular}

LAVI, left atrial volume index; SPAP, systolic pulmonary artery pressure; PE, pulmonary edema.

left heart to increase, and the pulmonary venous pressure and pulmonary capillary hydrostatic pressure increase accordingly (20). EVLW is composed of intracellular fluid, alveolar fluid and pulmonary interstitial fluid. It is a fluid distributed outside the pulmonary blood vessels (21). In general, the intracellular fluid is relatively fixed, and the alveolar fluid and interstitial fluid can change, reflecting the degree of PE $(22,23)$. The B-line in the lung ultrasound signs is a reverberation artifact, derived from the edema thickened subpleural lobular septum and the alveoli with increased water content $(16,24)$. The change in the number of B-line can reflect the change of EVLW, so lung ultrasound can be used to diagnose PE and monitor the effect of HF treatment.

The significant increase in pulmonary artery pressure and pulmonary capillary wedge pressure (PCWP) can be seen in patients with HF, it will cause changes in the ultrastructure of the pulmonary capillary wall, resulting in an increase in extravascular lung water (25). Through the quantitative monitoring and dynamic observation of extravascular pulmonary water, not only can the development and severity of $\mathrm{PE}$ be evaluated, but also the fluid therapy can be guided $(26,27)$. This is useful for understanding the pathophysiological changes and pulmonary function of cardiopulmonary diseases (14). A study (28) evaluated the left heart function of patients admitted to the cardiovascular department through the application of echocardiography and pulmonary ultrasound, the results have showed that the number of B-lines is related to the patients' New York heart function classification and left ventricular radiography, and LVEF is closely related to the degree of diastolic insufficiency. Besides, it's been reported that lung ultrasound examination can have a better predictive effect on the right heart pressure and PVR of patients with HF (29). In addition, more and more studies (30-32) have shown that the index value that can clearly represent the decompensation of heart function in patients with $\mathrm{HF}$ is closely related to the B-line. Several studies $(33,34)$ have found that lung ultrasound can detect PE and accurately detect changes in the amount of fluid in lung tissue before the early clinical symptoms of HF patients appear. Compared with traditional imaging techniques for displaying lungs such as chest X-ray or lung CT, pulmonary ultrasound needs to collect images of multiple parts of the lung, and the results of the examination need to be re-integrated (35). Therefore, it is necessary to select standardized operating procedures and make effective evaluations when performing pulmonary ultrasound examinations.

This study has certain limitations. Firstly, this study is a single-center study. Patients with atrial fibrillation and mitral stenosis were excluded from the study, but PE is not common among such patients (36). Secondly, due to the poor specificity of the B-line, it can only indicate the presence of pulmonary interstitial syndrome, but it cannot clearly show that the specific causes of PE. Therefore, it is necessary to combine specific etiology and medical history, patient clinical manifestations, and echocardiography in clinical application.

\section{Conclusions}

In conclusion, the results of this present study have indicated that the combined use of cardiopulmonary ultrasound is feasible and effective in the diagnosis of PE in patients with HF, which should be promoted in clinical settings. Furthermore, we have found that NT-proBNP $\geq 8,842.37 \mathrm{ng} / \mathrm{L}, \mathrm{LAVI} \geq 42.14 \mathrm{~mL} / \mathrm{m}^{2}, \mathrm{E} / \mathrm{e}^{\prime} \geq 19.20$, SPAP $\geq 38.16 \mathrm{mmHg}$ were the independent risk factors for $\mathrm{PE}$ in patients with $\mathrm{HF}$ (all $\mathrm{P}<0.05$ ), targeted strategies are needed for those patients.

\section{Acknowledgments}

Funding: None. 


\section{Footnote}

Reporting Checklist: The authors have completed the STARD reporting checklist. Available at http://dx.doi.org/10.21037/ cdt-20-733

Data Sharing Statement: Available at http://dx.doi. org/10.21037/cdt-20-733

Conflicts of Interest: All authors have completed the ICMJE uniform disclosure form (available at http://dx.doi. org/10.21037/cdt-20-733). The authors have no conflicts of interest to declare.

Ethical Statement: The authors are accountable for all aspects of the work in ensuring that questions related to the accuracy or integrity of any part of the work are appropriately investigated and resolved. The study was conducted in accordance with the Declaration of Helsinki (as revised in 2013). This present study had been verified and approved by the ethics committee of our hospital (No. 2018026), and written informed consents had been obtained from all included patients.

Open Access Statement: This is an Open Access article distributed in accordance with the Creative Commons Attribution-NonCommercial-NoDerivs 4.0 International License (CC BY-NC-ND 4.0), which permits the noncommercial replication and distribution of the article with the strict proviso that no changes or edits are made and the original work is properly cited (including links to both the formal publication through the relevant DOI and the license). See: https://creativecommons.org/licenses/by-nc-nd/4.0/.

\section{References}

1. Costanzo MR. The Cardiorenal Syndrome in Heart Failure. Heart Fail Clin 2020;16:81-97.

2. Kjeldsen SE, von Lueder TG, Smiseth OA, et al. Medical Therapies for Heart Failure With Preserved Ejection Fraction. Hypertension 2020;75:23-32.

3. Di Palo KE, Barone NJ. Hypertension and Heart Failure: Prevention, Targets, and Treatment. Heart Fail Clin 2020;16:99-106.

4. Adamo L, Rocha-Resende C, Prabhu SD, et al. Reappraising the role of inflammation in heart failure. Nat Rev Cardiol 2020;17:269-85.

5. Garcia AM, Beatty JT, Nakano SJ. Heart failure in single right ventricle congenital heart disease: physiological and molecular considerations. Am J Physiol Heart Circ Physiol 2020;318:H947-H965.

6. Raj L, Maidman SD, Adhyaru BB. Inpatient management of acute decompensated heart failure. Postgrad Med J 2020;96:33-42.

7. Fukata M. Acute Decompensated Heart Failure in Patients with Heart Failure with Reduced Ejection Fraction. Heart Fail Clin 2020;16:187-200.

8. Miyazaki K, Onuma Y, Komatsu R, et al. Development of Pulmonary Edema Despite Negative Fluid Balance with Diuretics in a Patient with Heart Failure and Sigmoid Septum. Tokai J Exp Clin Med 2020;45:31-6.

9. Ponikowski P, Voors AA, Anker SD, et al 2016 ESC Guidelines for the diagnosis and treatment of acute and chronic heart failure: The Task Force for the diagnosis and treatment of acute and chronic heart failure of the European Society of Cardiology (ESC). Developed with the special contribution of the Heart Failure Association (HFA) of the ESC. Eur J Heart Fail 2016;18:891-975.

10. Nussbaumerová B, Rosolova H. Diagnosis of heart failure: the new classification of heart failure. Vnitr Lek 2018;64:847-51.

11. Reddy YN, Borlaug BA. Heart failure with preserved ejection fraction. Curr Probl Cardiol 2016;41:145-88.

12. Brennan EJ. Chronic heart failure nursing: integrated multidisciplinary care. Br J Nurs 2018;27:681-8.

13. Lichtenstein DA. BLUE-protocol and FALLS-protocol: two applications of lung ultrasound in the critically ill. Chest 2015;147:1659-70.

14. Assaad S, Kratzert WB, Shelley B, et al. Assessment of Pulmonary Edema: Principles and Practice. J Cardiothorac Vasc Anesth 2018;32:901-14.

15. Platz E, Merz AA, Jhund PS, et al. Dynamic changes and prognostic value of pulmonary congestion by lung ultrasound in acute and chronic heart failure: a systematic review. Eur J Heart Fail 2017;19:1154-63.

16. Miglioranza MH, Picano E, Badano LP, et al. Pulmonary congestion evaluated by lung ultrasound predicts decompensation in heart failure outpatients. Int J Cardiol 2017;240:271-8.

17. Girerd N, Seronde MF, Coiro S, et al. Integrative Assessment of Congestion in Heart Failure Throughout the Patient Journey. JACC Heart Fail 2018;6:273-85.

18. Picano E, Pellikka PA. Ultrasound of extravascular lung water: a new standard for pulmonary congestion. Eur Heart J 2016;37:2097-104.

19. Martindale JL, Wakai A, Collins SP, et al. Diagnosing 
Acute Heart Failure in the Emergency Department: A Systematic Review and Meta-analysis. Acad Emerg Med 2016;23:223-42.

20. Wooten WM, Shaffer LET, Hamilton LA. Bedside Ultrasound Versus Chest Radiography for Detection of Pulmonary Edema: A Prospective Cohort Study. J Ultrasound Med 2019;38:967-73.

21. Martindale JL, Secko M, Kilpatrick JF, et al. Serial Sonographic Assessment of Pulmonary Edema in Patients With Hypertensive Acute Heart Failure. J Ultrasound Med 2018;37:337-45.

22. Gargani L. Ultrasound of the Lungs: More than a Room with a View. Heart Fail Clin 2019;15:297-303.

23. Palazzuoli A, Ruocco G, Beltrami M, et al. Combined use of lung ultrasound, B-type natriuretic peptide, and echocardiography for outcome prediction in patients with acute HFrEF and HFpEF. Clin Res Cardiol 2018;107:586-96.

24. Kochav SM, Flores RJ, et al. Prognostic Impact of Pulmonary Artery Pulsatility Index (PAPi) in Patients With Advanced Heart Failure: Insights From the ESCAPE Trial. J Card Fail 2018;24:453-9.

25. Guglielmini C, Diana A. Thoracic radiography in the cat: Identification of cardiomegaly and congestive heart failure. J Vet Cardiol 2015;17 Suppl 1:S87-101.

26. Thompson RB, Chow K, Pagano JJ, et al. Quantification of lung water in heart failure using cardiovascular magnetic resonance imaging. J Cardiovasc Magn Reson 2019;21:58.

27. Rademacher N, Pariaut R, Pate J, et al. Transthoracic lung ultrasound in normal dogs and dogs with cardiogenic pulmonary edema: a pilot study. Vet Radiol Ultrasound 2014;55:447-52.

28. Bailón MM, Rodrigo JMC, Lorenzo-Villalba N, et al. Effect of a Therapeutic Strategy Guided by Lung
Ultrasound on 6-Month Outcomes in Patients with Heart Failure: Randomized, Multicenter Trial (EPICC Study). Cardiovasc Drugs Ther 2019;33:453-9.

29. Ferré A, Guillot M, Lichtenstein D, et al. Lung ultrasound allows the diagnosis of weaning-induced pulmonary oedema. Intensive Care Med 2019;45:601-8.

30. Li H, Li YD, Zhu WW, et al. A Simplified Ultrasound Comet Tail Grading Scoring to Assess Pulmonary Congestion in Patients with Heart Failure. Biomed Res Int 2018;2018:8474839.

31. Martindale JL, Noble VE, Liteplo A. Diagnosing pulmonary edema: lung ultrasound versus chest radiography. Eur J Emerg Med 2013;20:356-60.

32. Martindale JL. Resolution of sonographic B-lines as a measure of pulmonary decongestion in acute heart failure. Am J Emerg Med 2016;34:1129-32.

33. Gargani L, Pang PS, Frassi F, et al. Persistent pulmonary congestion before discharge predicts rehospitalization in heart failure: a lung ultrasound study. Cardiovasc Ultrasound 2015;13:40.

34. Sforza A, Carlino MV, Guarino M, et al. A case of pulmonary edema: the critical role of lung-heart integrated ultrasound examination. Monaldi Arch Chest Dis 2018;88:982.

35. Öhman J, Harjola VP, Karjalainen P, et al. Assessment of early treatment response by rapid cardiothoracic ultrasound in acute heart failure: Cardiac filling pressures, pulmonary congestion and mortality. Eur Heart J Acute Cardiovasc Care 2018;7:311-20.

36. Platz E, Pivetta E, Merz AA, et al. Impact of device selection and clip duration on lung ultrasound assessment in patients with heart failure. Am J Emerg Med 2015;33:1552-6.
Cite this article as: Shen M, Chen H, Cong Y. Combined use of cardiopulmonary ultrasound in the diagnosis of pulmonary edema in patients with heart failure: a retrospective analysis. Cardiovasc Diagn Ther 2020;10(5):1325-1331. doi: 10.21037/ cdt-20-733 